\title{
Large-scale coordinated observations of Pc5 pulsation events
}

\author{
Zolile Mtumela $^{1}$, Anthony D. M. Walker ${ }^{2}$, Judy A. E. Stephenson ${ }^{2}$, and Michael J. Kosch ${ }^{1,3,4}$ \\ ${ }^{1}$ South African National Space Agency (SANSA), Space Science, P.O. Box 32, Hermanus, 7200, South Africa \\ ${ }^{2}$ School of Chemistry and Physics, University of KwaZulu-Natal, P/Bag X54001, Durban, 4000, South Africa \\ ${ }^{3}$ Lancaster University, Lancaster, LA1 4YB, UK \\ ${ }^{4}$ University of the Western Cape, Cape Town, 7535, South Africa
}

Correspondence to: Zolile Mtumela (zolilemtumela@gmail.com)

Received: 16 May 2016 - Revised: 12 September 2016 - Accepted: 15 September 2016 - Published: 29 September 2016

\begin{abstract}
HF (high-frequency) radars belonging to SuperDARN (Super Dual Auroral Radar Network) receive backscatter over substantial fields of view which, when combined, allow for simultaneous returns over extensive regions of the polar caps and midlatitudes. This makes them ideal instruments for the observation of pulsations in the Pc5 (1$5 \mathrm{mHz}$ ) frequency band. Relatively few pulsation events observed by multiple radars have been reported in the literature. Here we describe observations of three such events which extend over more than $120^{\circ}$ of magnetic longitude in the Northern Hemisphere and one of which is also detected in the Southern Hemisphere. All three events show characteristics of field line resonances. In one case the pulsation has also been observed by magnetometers under or near the radar fields of view. The extensive longitudinal coverage allows accurate determination of azimuthal wave numbers. These are at the upper end of the lower values associated with external sources such as those in the solar wind. Such sources imply antisunward flow. However, the azimuthal wave number is negative, implying westward propagation at magnetic local times on both sides of noon, as would be expected from drift-bounce resonance with positive particles. Quiet conditions and a very low ring current during the events argue against this. The identification of the source of pulsations from a number of different mechanisms remains a problem of interest.
\end{abstract}

Keywords. Magnetospheric physics (MHD waves and instabilities)

\section{Introduction}

Ultralow-frequency (ULF) pulsations arising from field line resonances and those in the Pc5 $(1-5 \mathrm{mHz})$ are global magnetohydrodynamic (MHD) events in the magnetosphere, which may extend over several hours of local time and be observed at magnetically conjugate locations. HF (high-frequency) radars are useful observing instruments because of their extensive fields of view and spatial resolution. They are, however, limited to periods when radar backscatter exists. Magnetometers, on the other hand, have poorer spatial resolution because the pulsation signal arises from the effects of the ionospheric currents associated with the pulsation and this is integrated over a transverse ionospheric region of dimensions comparable with the height of the ionosphere. Ideally, to get as complete a picture as possible, data from many instruments must be combined over as large a global range as available. The first pulsation study using an extensive magnetometer array was an investigation of a giant pulsation by Glassmeier (1980). Only a few pulsation events using multiple radars and coordinated magnetometers simultaneously observing a pulsation over an extensive range of longitude have been presented and analysed in the literature (e.g. Samson et al., 1991; Fenrich et al., 1995; Ziesolleck et al., 1998; James et al., 2013; Bland et al., 2014). Spacecraft observations over considerable spatial ranges, such as those by Agatipov et al. (2009), Balasis et al. (2012) and Balasis et al. (2015), have been rare.

Recently, (hereafter Paper 1; Mtumela et al., 2015) have reported a detailed case study of a magnetospheric field line resonance with a frequency in the Pc5 range using radars from SuperDARN (Super Dual Auroral Radar Network; Greenwald et al., 1995; Chisham et al., 2007) and 
the CARISMA (Canadian Array for Realtime Investigations of Magnetic Activity; Mann et al., 2008), Greenland (DTU Space, 2015), and IMAGE (International Monitor for Auroral Geomagnetic Effects; Tanskanen, 2009) magnetometer arrays. The global coverage of this event was substantially greater than in previous such studies (Fenrich et al., 1995; Ziesolleck et al., 1998). It extended over several hours of local time in the Northern Hemisphere. In this paper we extend the work of Paper 1 to include additional events with similar global coverage. In one case the study includes conjugate behaviour. We also consider the nature of the sources of such events and suggest a possible source for future investigation.

Pc5 field line resonances occur as the result of a compressional MHD oscillation exciting the magnetic shell with the same frequency into toroidal oscillation. When observed in the meridian plane the oscillation appears to be standing. There is generally phase advance in the azimuthal direction, which is characterized by the azimuthal wave number $m$. Various sources have been identified such as Kelvin-Helmholtz oscillations at the magnetopause (Southwood, 1968), excitation of cavity or waveguide modes (Kivelson and Southwood, 1985; Samson et al., 1992), direct control by oscillations in the solar wind (Stephenson and Walker, 2002), and more recently fluctuating field-aligned currents in the auroral zone (Pilipenko et al., 2016). Pulsations can also be generated by drift-bounce resonance with ring current particles (Dungey, 1965). These have shorter azimuthal wavelengths.

We review a number of mechanisms that have been proposed as the source of Pc5 pulsations. Our data allow us to eliminate many of these. The magnetic conditions effectively rule out drift-bounce particle resonance. Only studies such as this one, with observations over a number of hours of local time, can determine azimuthal wave number $m$ with reasonable confidence. The results imply that the source is located in the magnetotail and generates a fast wave that can excite the magnetospheric waveguide and hence trigger the field line resonances.

SuperDARN is well suited for the determination of spatial characteristics of ULF waves. In this paper three events, which were all unambiguously resolved by SuperDARN data as toroidal resonances, are presented. Each event analysis utilizes up to three radars in the network, which allows the pulsation to be monitored over a significant azimuthal extent of more than $40 \%$ of the Earth's circumference where it occurred. This in itself is a unique observation.

Identifying the energy source of Pc5 pulsations is an important and open question in space physics. The nature of the magnetosphere makes it a complex problem. However, SuperDARN has the ability to determine spectral information, azimuthal wave number, phase and group velocity, and polarization properties of the resonance. These parameters are essential clues to the generation mechanism and their determination in these events presented an unusual scenario of toroidal resonances with sunward phase velocities during extremely magnetically quiet conditions. This effectively rules out a number of popular candidates for the generation mechanism as discussed in the section "Source mechanisms". A different energy source is proposed here.

\section{Instrumentation}

Data from four SuperDARN HF (high-frequency) radars, located at Goose Bay (GBR), Saskatoon (SAS), Pykkvibær (PYK) and Sanae (SAN), were used in the analysis of three events. Table 1 gives the times, frequencies and locations of the three events analysed. In addition, data from the magnetometer arrays Greenland, CARISMA and IMAGE, were examined to verify the existence of pulsation data. Figure 1 shows maps in geographical coordinates of the northern and southern polar regions (inset), outlining the field of view of the radars and the locations of the magnetometer stations used for events 2 and 3. The corresponding map for event 1 is shown in Paper 1. The solid lines indicate the AACGM (Altitude Adjusted Corrected Geomagnetic Coordinates) magnetic latitudes (Baker and Wing, 1989; Shepherd, 2014).

There were good data for the Northern Hemisphere radars. In the south, Sanae observed no scatter for events 1 and 2. Sanae data for event 3 were analysable but sparse. We also examined other Southern Hemisphere radars in the same magnetic longitude sector. For events 1 and 3 Halley showed some activity in the region of interest, but the time series were not sufficiently continuous to analyse. For event $2 \mathrm{Hal}-$ ley showed no scatter in the region of interest. The only other relevant station, Syowa South, was not active at these times.

The radars of the system use an electronically phased antenna array to sweep the beam through successive beam positions with azimuthal separation of $3.24^{\circ}$. For each beam position returns are obtained from up to 75 ranges separated by $45 \mathrm{~km}$. In full scan mode a radar runs through a 16 beam scan with a dwell time of between 3 and $7 \mathrm{~s}$ (depending on radar), which gives a full scan that covers $52^{\circ}$ in azimuth once every 1 or 2 min.

The radars are sensitive to backscatter from field-aligned irregularities in the ionosphere. The nature of the backscattered signal and how it is measured are described by Greenwald et al. (1995). For such targets, they measure backscattered power, line-of-sight Doppler velocity and spectral width in the ionosphere in the cells mapped out by the scan. The Doppler velocity in each cell represents the component of velocity of the irregularities which experience an $\boldsymbol{E} \times \boldsymbol{B}$ flow parallel to the beam. Such line-of-sight Doppler velocities can be used to measure ULF oscillations in F region plasma flow associated with Pc5 field line resonance (see references in Paper 1).

The radars are also sensitive to ground scatter. Ponomarenko et al. (2003) have shown that ground scatter also can be used very effectively to observe ULF pulsations. Ground scatter can be identified by zero or very small line-of-sight Doppler velocities and very small spectral width. If the ray 


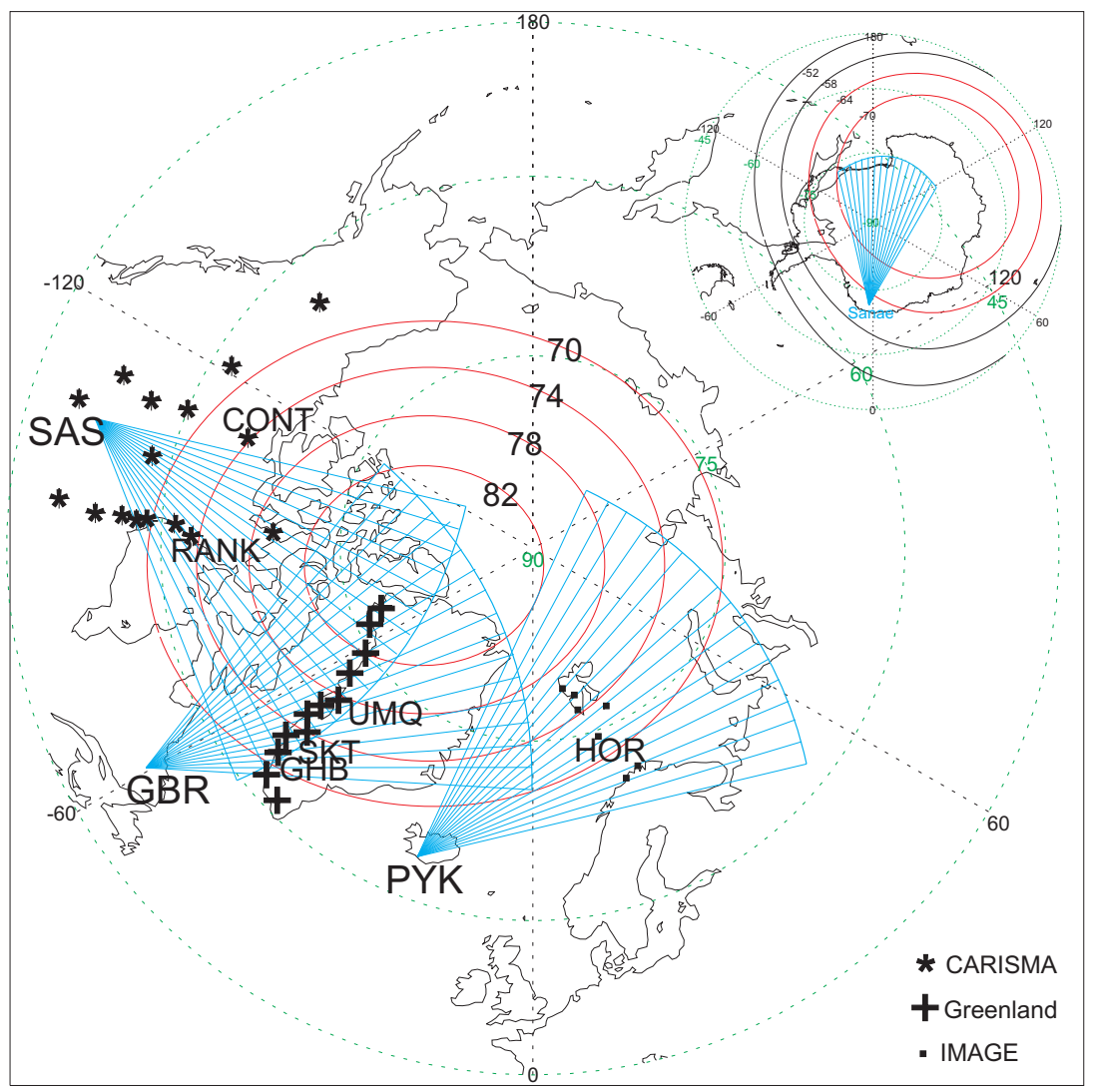

Figure 1. Fields of view of the SuperDARN radars at Saskatoon (SAS), Goose Bay (GBR) and Pykkvibær (PYK) and at Sanae (SAN) plotted (inset plot) in geographic coordinates. The solid lines are AACGM magnetic latitude for event $1\left(71-73^{\circ}\right)$, event $2\left(74-78^{\circ}\right)$ and event 3 $\left(78-82^{\circ}\right)$.

path of the radar signal is stationary, these quantities are zero. If, however, the ionosphere moves so that the path length changes (Poole et al., 1988), small $\left(<10 \mathrm{~m} \mathrm{~s}^{-1}\right)$ Doppler velocities may be observed in the ground scatter. There are several mechanisms giving rise to this shift. The two most significant are (i) a change in refractive index through compression of the plasma leading to changes in delay time and hence range and (ii) the vertical motion of the plasma as it is forced by the pulsation field to move up and down the magnetic field lines. When pulsations are observed in ground scatter, the measurements are not so directly related to the velocity perturbations associated with the plasma. The changes in radar range are quite small. As a result, the magnitude of the oscillation is typically only a few metres per second compared with a few hundred metres per second when the convection velocity is observed in the ionosphere using backscatter.

The ground-based magnetometer arrays cover polar cap, cusp and auroral regions as shown in Fig. 1. The large latitudinal coverage allows features such as the phase change across resonance and the amplitude peak of the wave to be observed. The longitudinal coverage provides information about the azimuthal wave number $m$. Each station can be identified using the accompanying key. The Greenland,
CARISMA and IMAGE magnetometer data are sampled every 20,1 and 10 s respectively in geographical $(X, Y, Z)$ coordinates and were rotated into geomagnetic $(H, D, Z)$ coordinates before analysis.

The magnetic latitude ranges within which resonance occurs for the events are $\sim 71-74^{\circ}$ (event 1 ), $\sim 74-78^{\circ}$ (event 2 ) and $\sim 78-82^{\circ}$ (event 3 ). The red curves in the figure indicate these regions for events 2 and 3. Radars and magnetometer stations considered in the study are labelled in Fig. 1 and listed in Table 1. Magnetic local times for observations during event 1 were all on the afternoon side. For event 2 all Saskatoon observations were on the morning side, Goose Bay was near noon and Pykkvibær near dusk. For event 3 Saskatoon was near noon and Goose Bay on the dusk side. At the time of these events magnetic conditions were quiet. For event $1 \mathrm{Kp}$ was 3 , for event 2 it was zero and for event 3 it was 3 . For all events the interplanetary magnetic field was northward. Ring current activity was small. During event 1 Dst varied from -3 to -4 , during event 2 from -3 to -2 and during event 3 from -4 to zero. 
Table 1. Events used in study. The latitude range is the nominal target range for Northern Hemisphere events, which were seen in ground scatter. Their pulsation location is at a lower latitude.

\begin{tabular}{ccccc}
\hline Event & Date & Time interval (UT) & Freq. band $(\mathrm{mHz})$ & Lat. range \\
\hline 1 & $06 / 10 / 2006$ & $20: 00-22: 00$ & $2.2-2.5$ & $71-74^{\circ}$ \\
2 & $06 / 10 / 2006$ & $16: 00-18: 00$ & $3.2-3.5$ & $74-78^{\circ}$ \\
3 & $14 / 09 / 2006$ & $18: 00-20: 00$ & $1.4-1.7$ & $78-82^{\circ}$ \\
\hline
\end{tabular}

Table 2. See Fig. 1 for map and key to station codes.

\begin{tabular}{ccc}
\hline Event & Radars & Magnetometer chains \\
\hline 1 & SAS GBR PYK & CONT SKT GHB HOR \\
2 & SAS GBR PYK & RANK UMQ \\
3 & SAS GBR SAN & \\
\hline
\end{tabular}

\section{Selection and analysis of data}

\subsection{Selection of events}

The method of selecting and analysing data is described in detail in Paper 1. Briefly, events were selected using a pulsation-finder software package developed by Magnus (2010). This scanned data from a particular radar to identify pulsation events where spectral peaks were 3 standard deviations above the ULF noise and where data were available over a large enough time interval and spatial region to be suitable for analysis. In practice the events used in this paper were first identified in the Goose Bay radar data by the pulsation finder. The Goose Bay radar was chosen to identify events because it had the best data returns during the periods scanned. A major objective of this work was to identify events with a large global extent. The data from adjacent and conjugate radars and magnetometers were searched for useful data. In addition magnetometer data sets from the neighbourhood of the radars were also examined. While pulsations are frequently observed by individual radars, events for which conditions are optimal at several radars are relatively rare. The three events used in this analysis were identified using this process.

The data for all radar cells and magnetometers used in an event were analysed using the same time interval as shown in Table 1. The location of the spectral peak had been determined by the pulsation finder, and the bandwidth is recorded in Table 1. Table 2 shows the instruments contributing to each event.

\subsection{Determination of resonance nature of events}

The next stage of the process was to confirm that each event showed characteristics consistent with field line resonance behaviour, namely a peak in the magnitude of the oscillation at a particular magnetic latitude and a decreas- ing phase as magnetic latitude increased. This was done for beams that were approximately aligned with the magnetic meridian. The theory of field line resonance (Tamao, 1965; Southwood, 1974; Chen and Hasegawa, 1974) shows that if an ideal pulsation is observed at points along a line of magnetic longitude the toroidal component has a strong peak at the resonance and the phase decreases by $180^{\circ}$ across the resonance. The poloidal component has little or no peak and a small phase change. At resonance the toroidal and poloidal components are in phase so that the polarization is linear. Calculations showing examples of this behaviour are shown by Walker (1980). There is, of course, also a phase dependence on longitude. Early radar observations, using the STARE VHF (Scandinavian Twin Auroral Radar Experiment very high-frequency) radar, obtained full vector information about the convection velocity so that the resonance behaviour could be unambiguously found. SuperDARN pulsation observations usually have the limitation that, because it is rare to have simultaneous observations of a pulsation using crossing beams from two radars, only the line-of-sight velocity component is available. The consequence is that, for observations using ionospheric backscatter, if the beam is exactly aligned with magnetic longitude, the poloidal component of the velocity dominates so that the peak in the amplitude and the magnitude of the phase change may be missed. If, on the other hand, the beam is aligned with magnetic latitude to see the toroidal component, we do not see the change of amplitude and phase across the resonance. Instead the phase change is associated with the azimuthal propagation.

If ground scatter is used for the observations, then, depending on conditions, transverse oscillations may perturb the ray path length. Poole et al. (1988), Sutcliffe and Poole (1989) and Sutcliffe and Poole (1990) considered various mechanisms for an ionosonde at vertical incidence (the SP model) and showed that the most important mechanism was the compression of the plasma as a result of vertical motion. This modified the refractive index so that the virtual path length changed. Other mechanisms also contributed. Waters et al. (2007) have considered oblique propagation and have shown that the dominant mechanism for pulsations is the vertical $\boldsymbol{E} \times \boldsymbol{B}$ drift due to the pulsation field, which affects the path through the SP mechanism. A limitation of such observations is that the perturbation occurs in the ionosphere where the pulsation is located, while the radar measured the range of the ground. The pulsation range is thus uncertain. The as- 

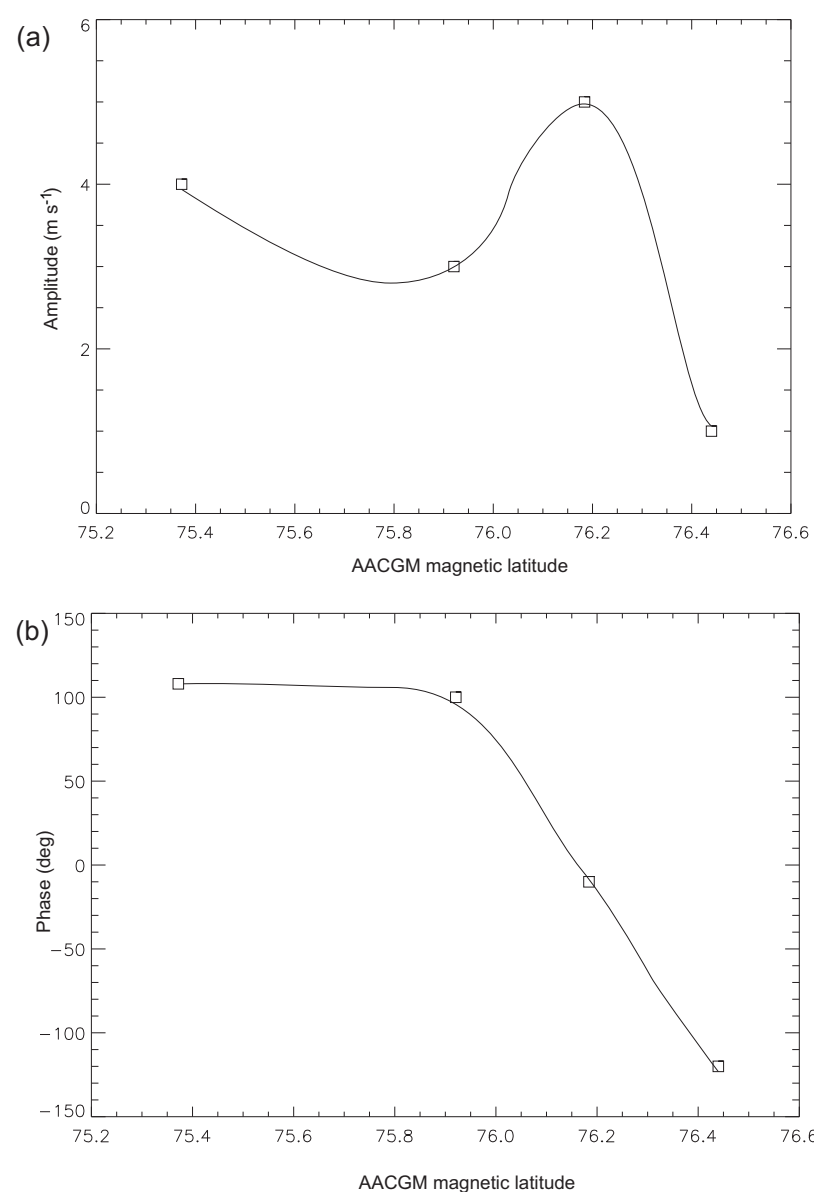

Figure 2. Latitude profile of amplitude and phase along beam 2 (beam aligned closely with the magnetic meridian) of Pykkvibær for event 2 .

sumption that the pulsation is located halfway between the antenna and the ground target is not necessarily true.

For both types of backscatter the best compromise is to choose beams approximately aligned with longitude so that the phase change is obvious, even though the peak may be small. The best beam alignment to observe classic resonance features makes a relatively small angle with the meridian so that the much larger toroidal component makes a significant contribution while the azimuthal phase change is still small. It is important to note, however, that near the resonance maximum, toroidal and poloidal components are in phase, so that phase measurements are unambiguous.

The resonance behaviour of event 1 was verified in $\mathrm{Pa}$ per 1. That for events 2 and 3 is shown in Figs. 2 and 3 respectively. In each case the behaviour is consistent with a field line resonance. Figure 2 shows a quite a strong resonant peak, implying that a significant component of the toroidal oscillation is included and phase change is consistent with resonance. The peak is weaker in Fig. 3, but the features are still consistent with resonance.
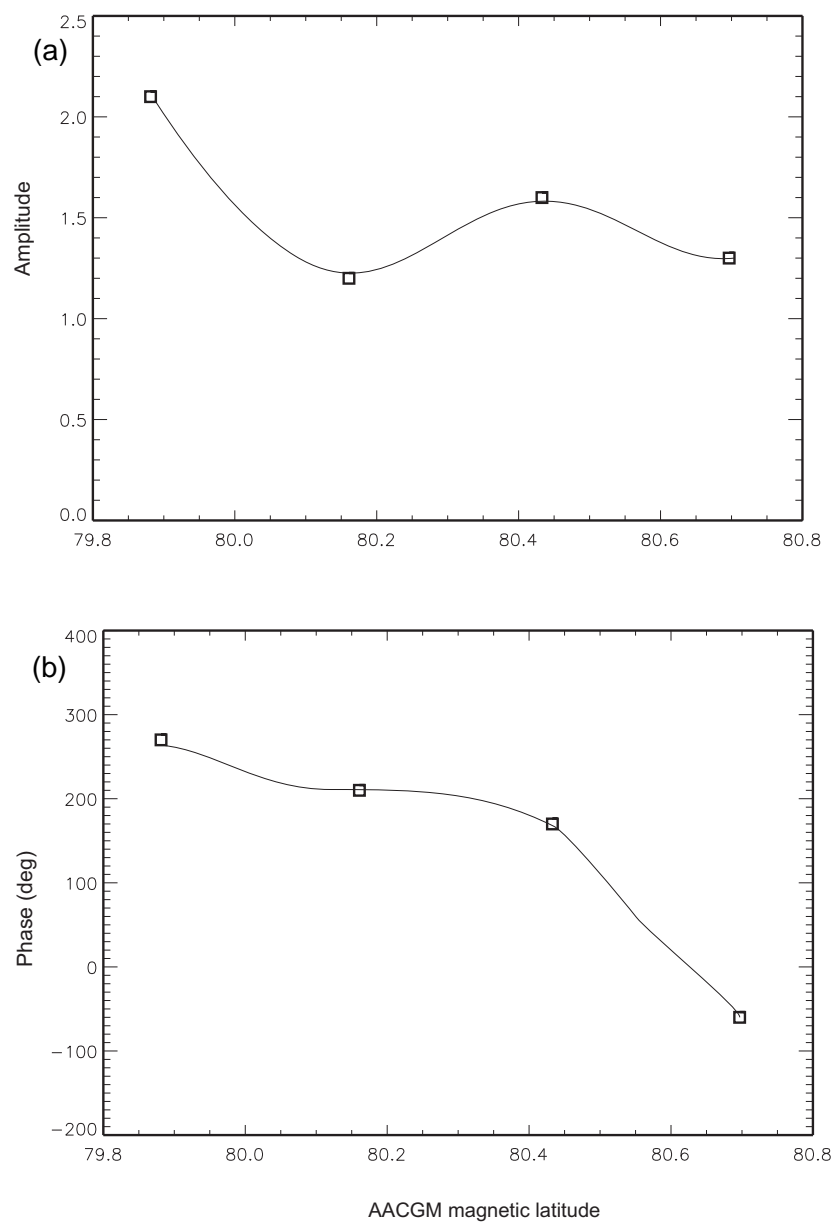

Figure 3. Latitude profile of amplitude and phase along beam 7 (beam aligned closely with the magnetic meridian) of Saskatoon for event 3 .

\subsection{Analysis procedure}

Data from radar cells for the complete available range of longitudes in a latitude band on either side of resonance were analysed by complex demodulation as described, for example, by Walker et al. (1992). Each time series was Fourier analysed, the negative frequency components were removed and the spectral peak bandpass filtered using the pass band in Table 1 . The result was a complex time series whose real part was the filtered time series, with amplitude representing the instantaneous amplitude of the signal and with phase representing the instantaneous phase. The data set in this form is what is used in extracting the results that follow.

\section{Results}

Figure 4 shows examples of the analysis for event 2 . This is for Goose Bay, beam 9. Beam 9 is approximately in the magnetic meridian. The top panel represents the filtered real time series, that is, the real part of the analytic signal calculated 

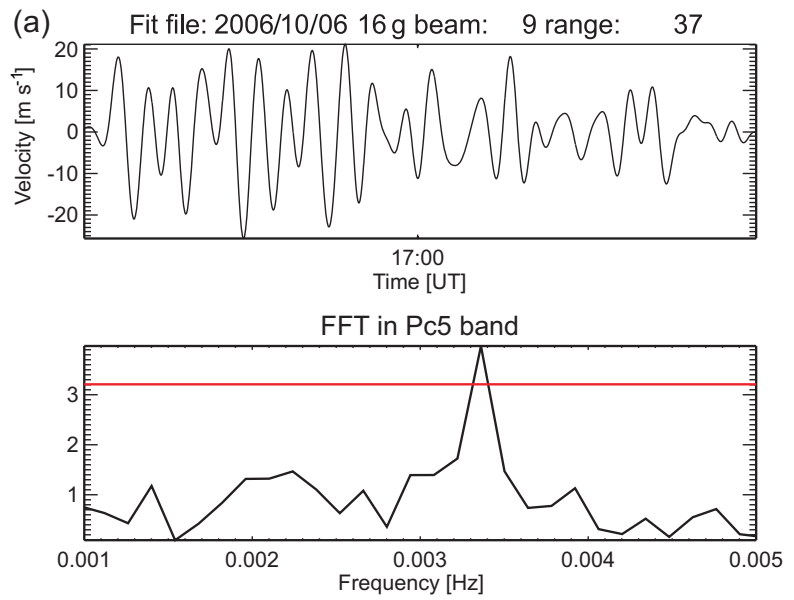

(b)

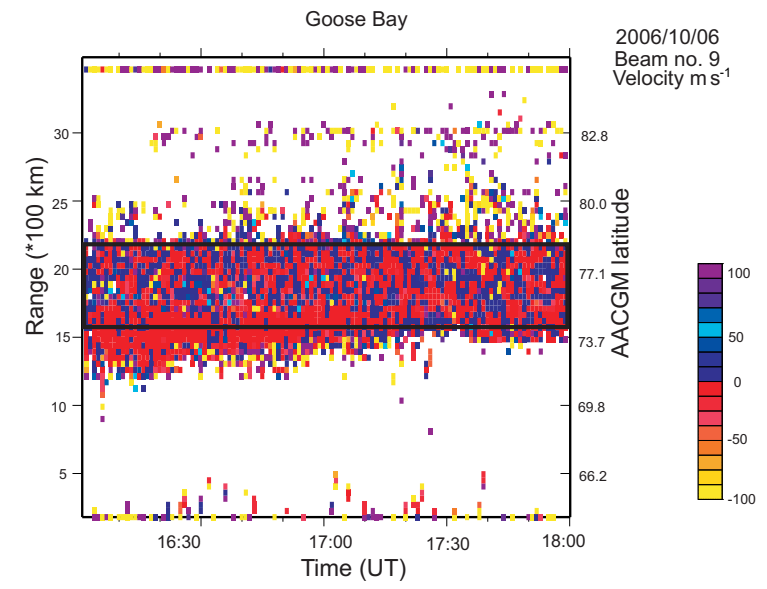

Figure 4. Event 2: (a) the top panel shows Pc5 band-filtered Doppler velocity data from the Goose Bay radar. The lower panel contains the corresponding power spectrum together with the significant limit level from filtered data. The peak detector recorded the peak in frequency band $3.2-3.5 \mathrm{mHz}$ as significant. (b) A timerange summary plot of Doppler velocity in metres per second measured by beam 9 of Goose Bay radar showing range and AACGM latitude.

above. It shows the oscillatory properties of the pulsation at the resonance latitude. For those with doubts about the significance of the signal, the lower panel in (a) shows the Fourier transform of the data obtained by the pulsation finder. The red line is a level that is 3 standard deviations above the noise level in the Pc5 band. The third panel is the time series plot of the line-of-sight Doppler velocity. This is colour coded according to the colour bar on the right of the diagram. Positive velocities (blue to violet on the colour bar) are towards the radar; negative velocities (red to yellow) are away from it. The range is expressed in kilometres. Range gates are $45 \mathrm{~km}$ in extent and range gate zero is located $180 \mathrm{~km}$ from the radar so that range gate no. 37 , used for the calculations in the panel (a), is at a range of $180+37 \times 45 \mathrm{~km}=1845 \mathrm{~km}$. The right-hand axis shows the AACGM magnetic latitude. The range shown is the range of the target, which in this case is
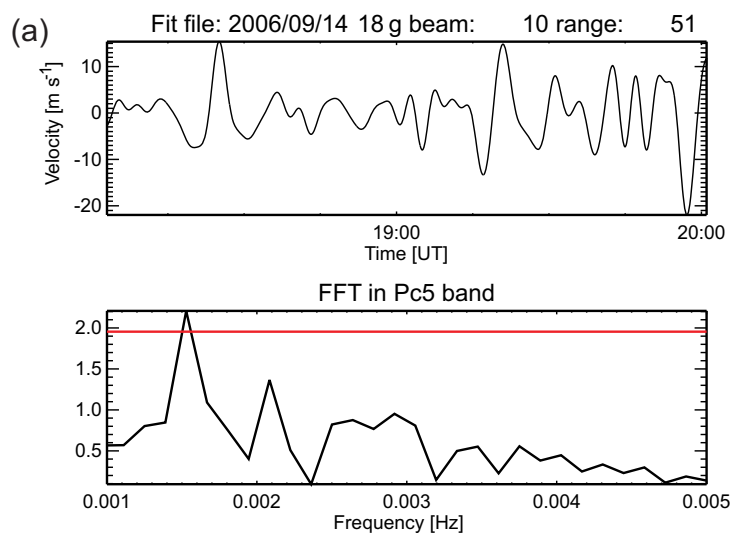

(b)

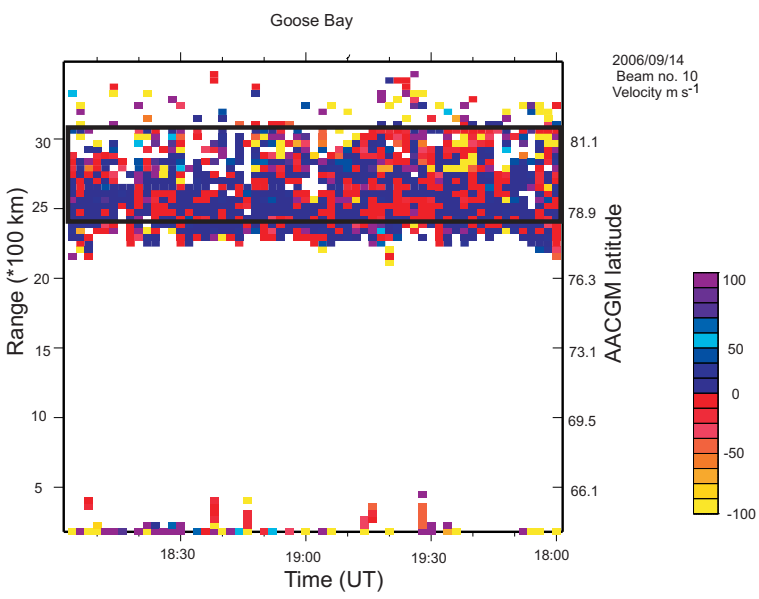

Figure 5. Event 3: (a) the top panel shows Pc5 band-filtered Doppler velocity data from the Goose Bay radar. The lower panel contains the corresponding power spectrum together with the significant limit level from filtered data. The peak detector recorded the peak in frequency band $1.4-1.7 \mathrm{mHz}$ as significant. (b) A timerange summary plot of Doppler velocity in metres per second measured by beam 10 of Goose Bay radar showing range and AACGM latitude.

the ground. The actual pulsation range is in the ionosphere, roughly halfway between the target and the radar. Similar plots are shown in Paper 1 for event 1 at Goose Bay and in Figs. 5 and 6 for event 3 at Goose Bay and Saskatoon respectively.

The data presentation for Sanae (see Fig. 7) in the conjugate hemisphere is somewhat different. The backscatter in this case is from irregularities in the ionosphere. Although the velocities are small, there is no possibility of ground scatter because a ray tracing test shows that the range is well within the skip distance. There are three peaks in the spectrum, of which the middle one, centred on $1.55 \mathrm{mHz}$, is at the frequency of interest. The bottom panel shows stacked plots of the unfiltered data.

These events are observed over a very wide range of longitudes (about $150^{\circ}$ for events 1 and 2 and about $120^{\circ}$ for 
(a)
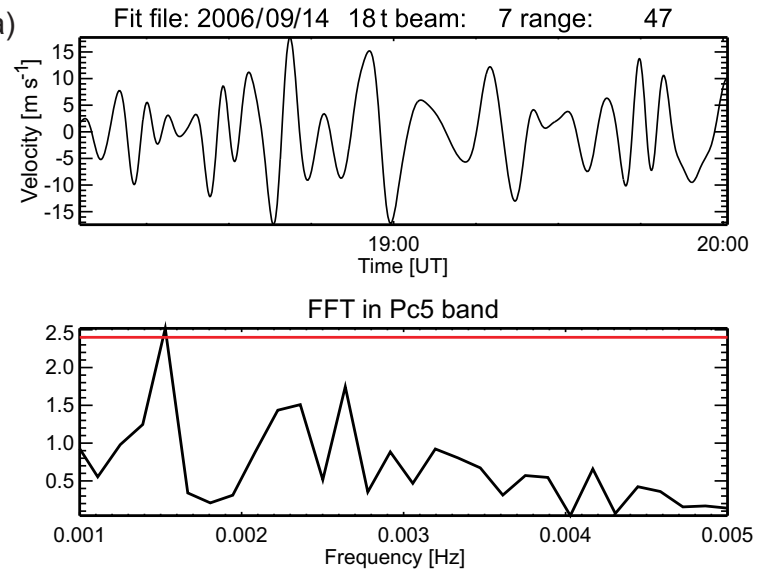

(b)

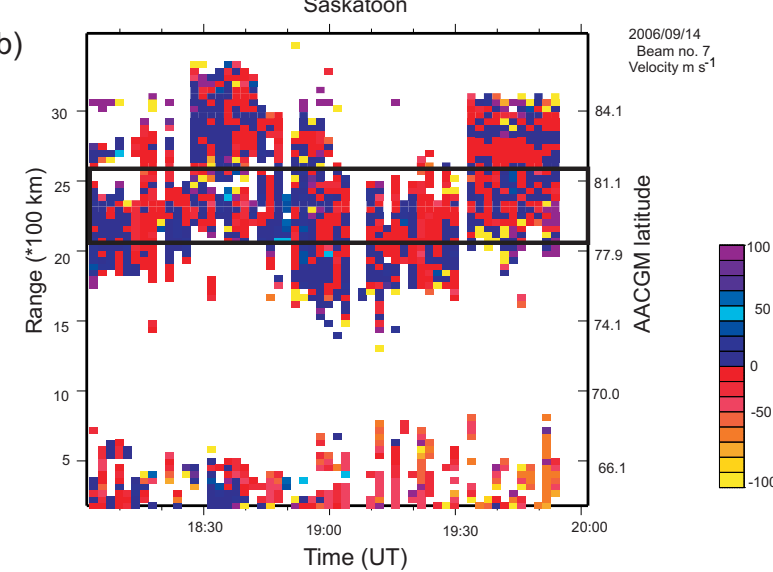

Figure 6. Event 3: (a) the top panel shows Pc5 band-filtered Doppler velocity data from the Saskatoon radar. The lower panel contains the corresponding power spectrum together with the significant limit level from filtered data. The peak detector recorded the peak in frequency band $1.4-1.7 \mathrm{mHz}$ as significant. (b) A timerange summary plot of Doppler velocity in metres per second measured by beam 7 of Saskatoon radar showing range and AACGM latitude.

event 3). They are truly global, extending over more than a third of the Earth's circumference on the afternoon side.

Examples of the power spectra of the $H$ component of the magnetometer data are shown in Figs. 8 and 9. In these figures the shaded regions are the frequency bands in which the Pc5 events are observed by the radars. In Fig. 8 the spectra during event 1 are shown for CONT in the field of view of Saskatoon, SKT and GHB in the field of view of Goose Bay, and HOR in the field of view of Pykkvibær. In Fig. 9, similar plots are shown for event 2. RANK and UMQ are in the fields of view of Saskatoon and Goose Bay respectively. In some cases there is a well-defined spectral peak in the frequency band; in others it is weak. Because the radar observations are made in the ground scatter, the exact location of the resonance maximum is not precisely known. The stations showing the weakest peaks are probably some dis-

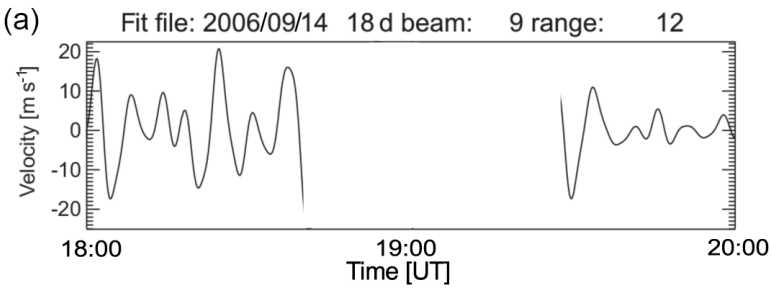

(b)

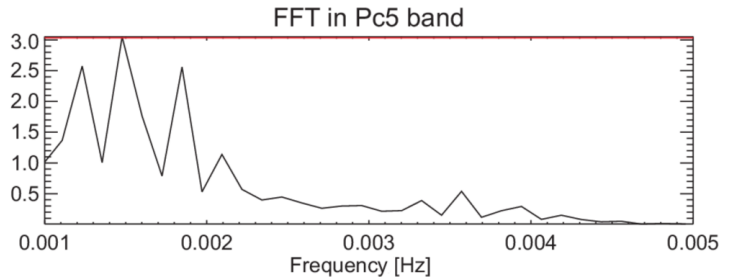

(c)

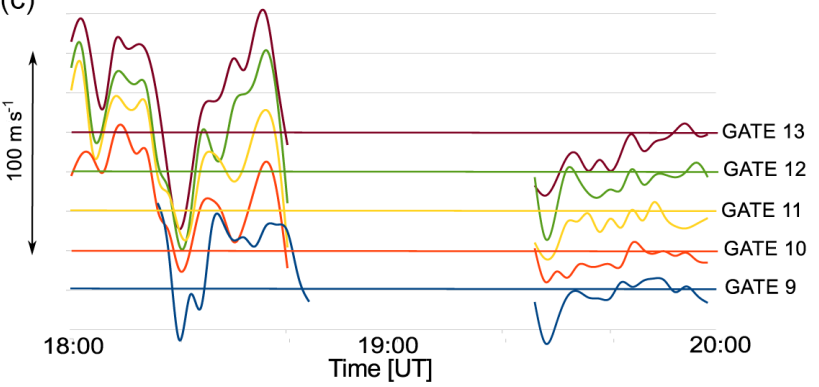

Figure 7. Event 3. The top panel (a) shows Pc5 band-filtered Doppler velocity data from the Sanae radar. The middle panel (b) contains the corresponding power spectrum together with the significant limit level from filtered data. The peak detector recorded the peak in frequency band $1.4-1.7 \mathrm{mHz}$ as significant. The bottom panel (c) is a stack plot of the velocity data in the range gates showing the strongest activity.

tance from the resonance maximum. There is, however, confirmation that the oscillation is also seen in the magnetometer data.

An important feature of the behaviour that contributes to the possibility of determining the source of the event is the sense of the phase propagation in the azimuthal direction. If $\phi$ is the magnetic longitude, increasing eastward, and the signal varies as $\exp \{i(\omega t-m \phi)\}$, then, if the azimuthal wave number $m$ is positive, the direction of phase advance is eastward and vice versa.

For each radar used in the study, range gates in each beam that are closest to the estimated range of the resonance maximum have been selected. The phase of the analytic signal at the time of maximum pulsation activity has been plotted against AACGM latitude, and a least-squares straight-line fit to the data has been carried out. Examples of such plots for Event 1 are shown in Paper 1. For each of the radars Saskatoon, Goose Bay and Pykkvibær, the slope of the plot is positive, implying a negative value of $m$ and westward propagation. Furthermore, the three values of $m$ obtained were very similar, namely $12 \pm 2.1$ (Saskatoon), $13 \pm 2.9$ (Goose Bay) 


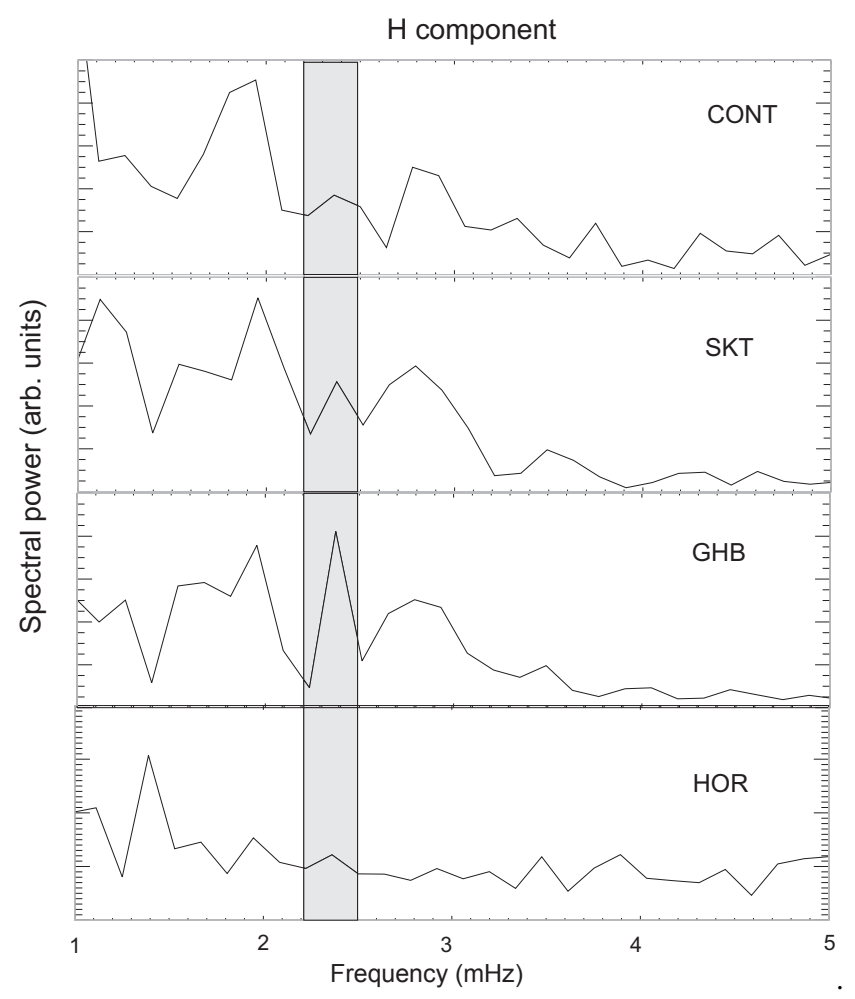

Figure 8. Event 1, the spectral power for the magnetometer stations (CONT, SKT, GHB and HOR). They are plotted so that top to bottom is west to east. (Adapted from Mtumela et al., 2015.)

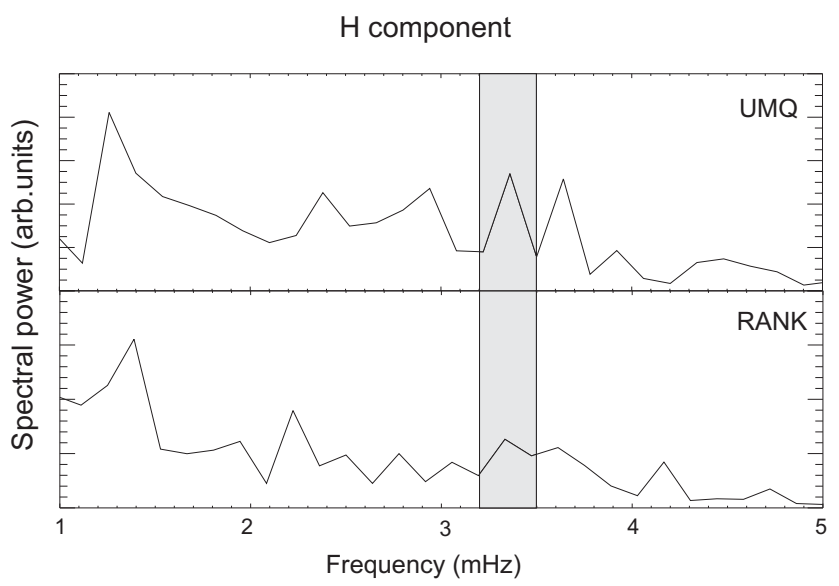

Figure 9. Event 2, the corresponding spectral power for the magnetometer stations (UMQ (Greenland) and RANK (CARISMA)).

and $19 \pm 5.0$ (Pykkvibær). These are in the range of values typical of classic pulsations. Fenrich et al. (1995) selected $m=17$ as the division between classic field line resonances and high $m$ energetic particle-driven pulsations. The phases obtained from the data are, of course, cyclic with a period of $2 \pi$. Thus, there is a phase difference ambiguity of $2 n \pi$ in the relative phases of the two radars. The values for Saskatoon and Goose Bay are sufficiently close to suggest a nearly

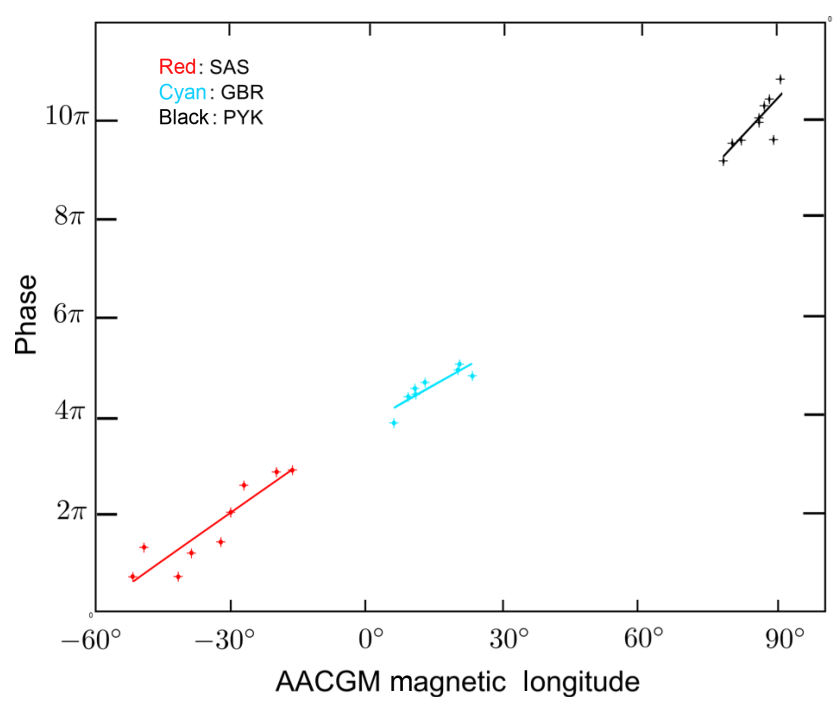

Figure 10. Event 1. Consolidated plot of phase as a function of AACGM latitude across the fields of view of the Saskatoon, Goose Bay and Pykkvibær radars.

constant wavelength between them. In Fig. 10 they are plotted on the same axes on the assumption that, if the Saskatoon and Goose Bay are extrapolated backwards and forwards, the straight lines will approximately coincide. This allows us to estimate the phase ambiguity by adding a suitable multiple of $2 \pi$ to one of the stations. As noted in Paper 1, the value of $m$ for Pykkvibær is larger, which might suggest a change in phase velocity with latitude. Nevertheless, this value has a relatively large error estimate and, in fact, the error estimates of the data for the three stations overlap. We have thus also plotted the Pykkvibær data on the same plot. We have not in this case derived a mean value for $m$ as the phase ambiguity for Pykkvibær is subject to error.

The procedure has been adopted for the other two events. For event 2 we obtain $m$ values of $7 \pm 3.2$ for Saskatoon, $9 \pm 2.3$ for Goose Bay and $9 \pm 4.3$ for Pykkvibær. The results are shown in Fig. 11a. In this case we are confident enough to fit a straight line to all three events, getting $m=8.0 \pm 0.3$ for the combined data set. Similarly, for event 3 the $m$ values for the individual radars were $9 \pm 2.4$ for Saskatoon and $9 \pm$ 4.3 for Goose Bay. The consolidated plot shown in Fig. 11b gives a value of $m=8.0 \pm 0.5$. Note that this value from the combined plot is lower than either individual plot. The errors on the individual plots are fairly large but not so large that the relative phase ambiguity could be $2 \pi$ different.

The data from Sanae show a spectral peak at the correct frequency for event 3 in the opposite hemisphere. Unfortunately, as can be seen from Fig. 7, there is a fairly large data gap in the data, and phase information at the time of the maximum activity is not available. It is introduced here in order to consider conjugate behaviour of the pulsation. The nominal latitude in the Southern Hemisphere is significantly different 

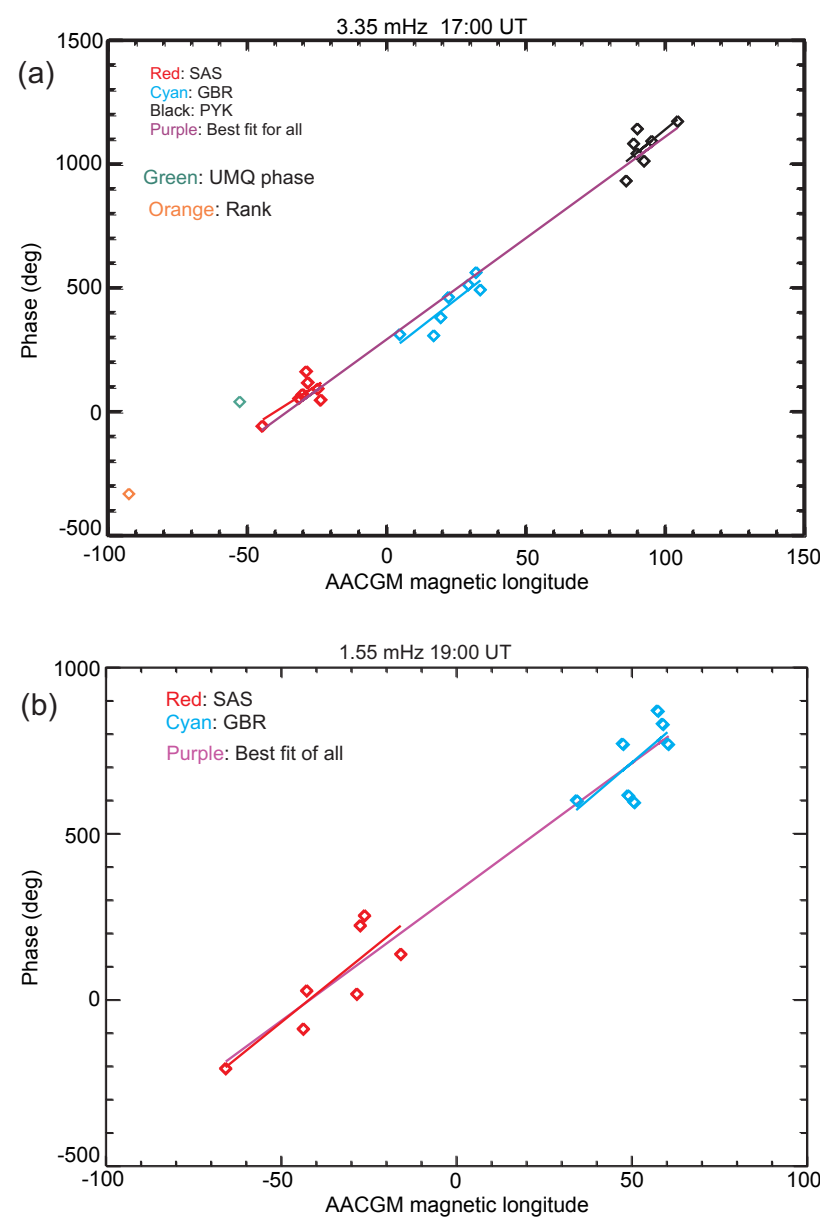

Figure 11. Event 2: (a) plot of phase versus longitude measured at 17:00 UT for the $3.35 \mathrm{mHz}$ frequency. The slope of this relation yields the azimuthal wave number $m: 7 \pm 3.2$ for Saskatoon (red), $9 \pm 2.3$ for Goose Bay (cyan) and $9 \pm 4.3$ for Pykkvibær (black), corresponding to a westward phase velocities at the ionosphere. The $m$ value of the three radars is $\sim 8 \pm 0.3$ (purple). The phase of the resonance from the magnetometers RANK and UMQ were determined and plotted (green: UMQ; orange: RANK). (b) Event 3: plot of phase versus longitude measured at 19:00 UT for the $1.55 \mathrm{mHz}$ frequency for event 3 . The slope of this relation yields the azimuthal wave number $m: 9 \pm 2.4$ for Saskatoon (red) and $9 \pm 4.3$ for Goose Bay (cyan), corresponding to a westward phase velocity at the ionosphere. The $m$ value of the two radars is $\sim 8 \pm 0.5$ (purple).

from that in the north. However, as we have noted above, the Sanae data are from half-hop backscatter, while the Northern Hemisphere data are from one-hop ground scatter. The northern pulsation location is in the ionosphere on the ray path somewhere between the radar and the ground target. Ray tracing shows that the paths of the ground scatter rays in the Northern Hemisphere pass through the ionosphere at the points conjugate to the Sanae backscatter region. This suggests that we are indeed seeing conjugate pulsations for event 3 .
For event 2 in Fig. 11a we have also plotted the phase of the UMQ and RANK magnetometers. Magnetometer pulsations are not well resolved in latitude because of the integrating effect of the ionosphere. These stations are well removed from the resonance, which means that the phase is likely to be largely from the poloidal component which is close to the resonance phase.

\section{Source mechanisms}

ULF pulsations in the Pc5 frequency range have a variety of origins. The determination of the source mechanism is not trivial. Because the pulsations are global phenomena, a full set of observations covering the whole extent of the phenomenon requires good fortune in finding coincident data sets from a variety of instruments both in the ionosphere or on the ground and in spacecraft near the magnetic equatorial plane.

Pc5 pulsations observed on the ground or in the ionosphere are the footprints of the characteristic modes of oscillation of the magnetosphere. Two types of standing wave were first identified by Dungey (1954). In the case of small $\beta$, the fast wave becomes an isotropic Alfvén wave. In general, the MHD wave equation, in the complicated geometry of the magnetosphere, is not separable into isotropic and transverse Alfvén modes; these modes are strongly coupled by the geometry. In some circumstances separation is possible. The two cases are (i) $m=0$, for which a single $L$ shell can oscillate in the toroidal direction as a transverse Alfvén mode, and (ii) $m \rightarrow \infty$, in which a single field line can oscillate incompressibly in the poloidal direction, also as a transverse Alfvén mode. The second of these can be excited by driftbounce resonance with energetic ring-current particles. The first, in its ideal form, is not easily excited. If, however, $m$ is small, there is weak coupling between the poloidal isotropic Alfvén mode and the toroidal mode if their frequencies are the same. The isotropic wave can propagate energy across field lines, transporting it from a remote source to an $L$ shell whose natural frequency of oscillation matches that of the source where coupling takes place. This results in the socalled field line resonance.

Consider Fig. 12. It shows the value of the DST (disturbance storm time) index for intervals straddling the three events studied. In each case the magnitude of DST is very small, implying that the ring current is also very small. Indeed, for such values of DST the ring current is essentially absent. For this reason we reject the possibility of a driftbounce resonance with energetic ring current particles as a source of the observed pulsations. In addition, they show features consistent with field line resonances. This leads us to conclude that the pulsations originate from a remote source and are propagated by a fast wave to the location of the field line resonance. 

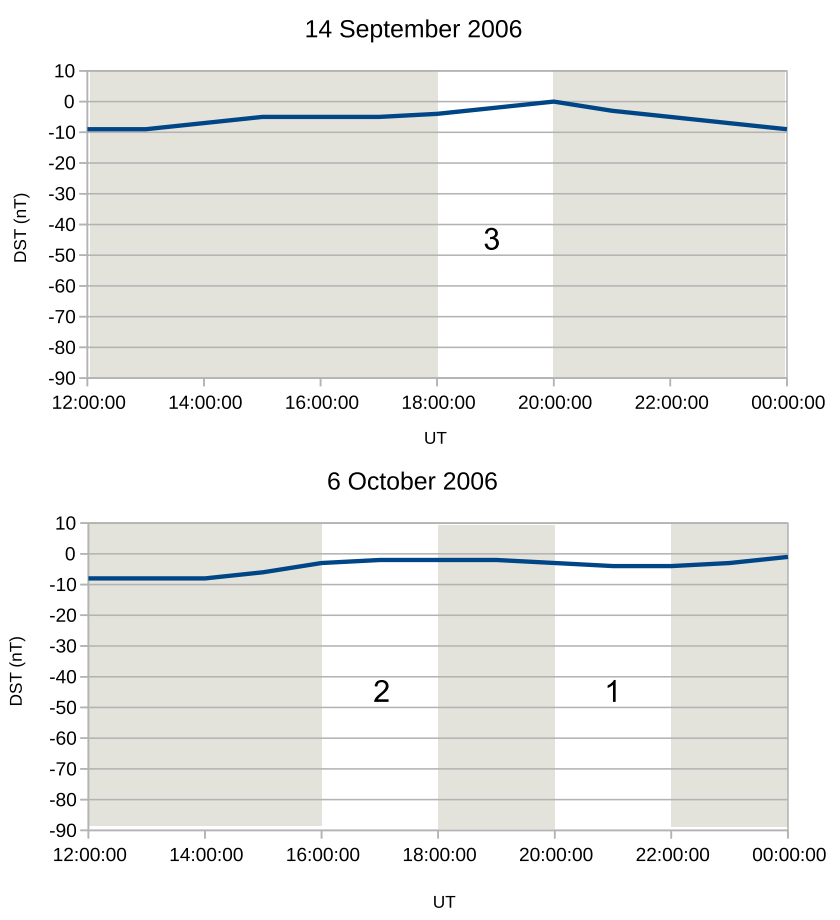

Figure 12. DST during the periods of interest. The labelled, unshaded portions represent the three events studied.

A number of mechanisms have been suggested for exciting such waves. Consider Fig. 13, which is adapted from Fig. 9 of Walker (2002). It shows the equatorial plane of the magnetosphere in a simple model in which the field lines have been straightened. We discuss various mechanisms in the context of this model. Outside the plasmapause, the Alfvén speed decreases with radius. The isotropic Alfvén wave is reflected at the turning point where $V_{\mathrm{A}}=\omega / \sqrt{k_{y}^{2}+k_{z}^{2}}$ with $k_{y}=m / r$ (Walker, 2002). This radius is shown for various frequencies in the figure for the case where $m$ lies between 1 and 3. The value of $k_{z}$ corresponds to a field line length of $20 R_{\mathrm{E}}$ so that it is small compared to $k_{y}$. For larger values of $m$, the reflection level is at a smaller value of $V_{\mathrm{A}}$ and thus at a somewhat larger radius. For larger values of $m$, the reflection levels would be at slightly larger radii, but the dependence of $r$ on $m$ is quite weak. The resonance level for each frequency is at the radius where $V_{\mathrm{A}}=\omega / k_{z}$, which lies inside the turning point.

For each frequency the isotropic Alfvén wave can be propagated outside the reflection at the turning point and it is evanescent inside this. We see that, for these conditions, the reflection level for the lowest frequency $(1.3 \mathrm{kHz})$ intersects the magnetopause in the noon sector. The region of evanescence extends to the magnetopause for this case. For the higher frequencies the region just inside the magnetopause allows propagation of the isotropic Alfvén wave.

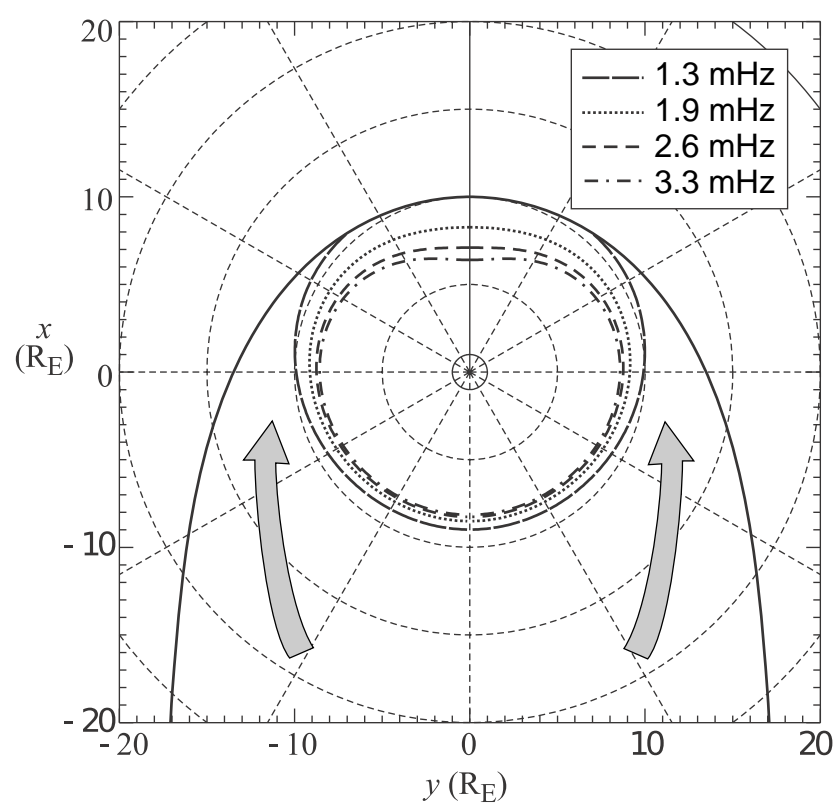

Figure 13. Magnetospheric equatorial plane showing turning points for fast wave at several frequencies. The large grey arrows indicate the direction of a fast wave propagated from the tail into the waveguide. (Adapted from Walker, 2002.)

We now consider a number of mechanisms that have been proposed as the source of the compressional wave that transfers energy to the field line resonance.

The earliest of these was the Kelvin-Helmholtz instability (Southwood, 1968; Walker, 1981). This is an instability of the fast wave as a result of the shear across the magnetopause. A small perturbation in the boundary grows if the shear is large enough provided that the boundary conditions determine a surface wave. This requires the wave on either side of the boundary to decrease exponentially on either side of the boundary to confine the energy. The energy can leak to the resonance by evanescent barrier penetration. The rest frame of the wave is that for which the momentum densities of the plasma on either side of the boundary are equal and opposite. In the rest frame of the magnetosphere, the magnetosheath speed is much larger than the convection speed and thus, when the wave is observed from this frame, its phase motion is antisunward. As we see from Fig. 13 the instability tends to occur only for the lowest frequencies, near the front of the magnetosphere. Since our observations show sunward phase motion on the flanks of the magnetosphere, we reject the Kelvin-Helmholtz instability on the magnetopause as a source.

Several other mechanisms depend on the model proposed by Kivelson and Southwood (1985). They noted that the magnetopause and the turning point level formed the boundaries of a cavity with natural frequencies of oscillation. These modes could be excited by a suitable disturbance. The picture was modified by Samson et al. (1992), who pointed out 
that the cavity behaved more like a waveguide. These authors envisaged the cavity being excited by a broadband impulse originating from the solar wind. Other ways of exciting the cavity include the mechanism of Mann et al. (1999), who showed how the overreflection mechanism could extract energy from the shear motion at the boundary. Observations of some events show correlation with coherent waves in the solar wind (Kepko et al., 2002; Stephenson and Walker, 2002). These can excite the cavity modes (Walker, 2002) and hence excite the field line resonance.

All these mechanisms excite cavity waves with phase motion in the antisunward direction and therefore cannot explain our observations. We must seek an isotropic Alfvén wave source elsewhere.

In Fig. 13 the whole magnetotail region allows propagation of the compressible magnetohydrodynamic wave. In the plasma sheet region, where the plasma pressure is significant, this is the fast magnetosonic wave. As we move towards the Earth the magnetic field pressure becomes larger and the fast wave approximates the isotropic Alfvén wave. A source of such waves in the tail would provide waves propagated sunwards towards the waveguide as indicated by the large grey arrows in the figure. In general, there would be a mismatch between this wave and a wave propagated in the wave guide. If, however, the spectrum of the signal contained frequencies matching the frequencies of the waveguide modes, these modes would be excited and would be propagated sunwards in the waveguide, exciting the field line resonances of the type observed here. Mathews et al. (2004) and Eriksson et al. (2008) have also observed field line resonances with sunward phase propagation and suggested that they were generated by earthward flows in the magnetotail. Early radar observations of such field line resonances by Nielsen (1979), using the STARE VHF radar, associated them with large disturbances of the drift velocity on the afternoon side of the magnetosphere. They suggested that these disturbances were the footprint of a flux transfer event.

These events occurred during very quiet magnetic conditions. As we have seen, the DST index was essentially zero. The magnetic field in the solar wind as observed by ACE (Advanced Composition Explorer) is about $3 \mathrm{nT}$ or less, with $B_{z}$ less than $2 \mathrm{nT}$ and northward. The SuperDARN convection maps show a simple two-cell convection pattern. We have been unable to find any data that would help to identify a specific source in the tail. Neither Geotail nor the Cluster group is favourably placed at these times. No SuperDARN radars were suitably located. We can, however, consider the conditions in order to suggest a possible source.

At quiet times such as these with northward interplanetary $B_{z}$, the magnetotail is not static. There are numerous observations of so-called "Tail Reconnection during IMFNorthward Non-substorm Intervals" (TRINNI) events (Grocott et al., 2005, and references therein) involving local reconnection and dipolarization of the tail magnetic field. The precise behaviour is influenced by $B_{y}$ (Grocott et al., 2004).
They can produce large quasiperiodic disturbances of the drift velocity (Walker et al., 1998, 2002).

We suggest that, under these magnetic conditions, there are likely to be TRINNI reconnection events in the tail. If so, they would form a strong source of fast MHD waves propagated sunwards and exciting the waveguide as described above. Field line resonances would then be excited by the usual mechanism of leakage from the waveguide. An investigation of this hypothesis is being undertaken.

\section{Discussion and conclusions}

In this paper we have presented observations of several long period events over an unusually large range of longitudes. Their properties can be briefly summarized as follows:

- Their frequencies are in the Pc5 range $(1.6-3.3 \mathrm{mHz})$, with the lowest frequency on the boundary between the Pc5 and Pc6 bands.

- Their longitudinal extent is more then $120^{\circ}$ on the afternoon/dusk side.

- In one case there is an oscillation at the same frequency observed in the other hemisphere.

- Their azimuthal wave numbers $(\simeq 7-12)$ are well below $m=17$, the upper limit for a classic field line resonance.

- The sense of azimuthal phase propagation is westward.

Pc5 disturbances can be quite large with drift velocity amplitudes of several hundreds or even exceeding a thousand metres per second. For these events it has not been possible to estimate the amplitude because the bulk of the observations are derived from ground scatter. In such cases the radars do not measure the drift velocity, but the effective rate of change of the HF path length as a result of the refractive index changes because of compression driven by the pulsation fields. It should be noted that the very small observed Doppler velocities do not imply small drift velocities.

These events appear to be truly global extending over an azimuthal range of more than one third of the Earth's circumference in the Northern Hemisphere. The nature of the conjugate behaviour is not well determined. Because the Northern Hemisphere observation are derived from ground scatter, the exact location of the footprint of the pulsation is uncertain. The Southern Hemisphere data are sparse and only exist for one radar and one event, where the observations come from ionospheric backscatter and determine a latitude range within which the pulsation footprint is located. The ionospheric part of the ray path of the ground-scattered signal in the northern conjugate region includes this latitude range. This is indicative of conjugate behaviour of the pulsation but does not establish it definitively.

The source of the pulsations in these events has been discussed in detail. Particle drift-bounce resonance can be ruled 
out because of the extremely quiet conditions and near-zero ring current. Also, the $m$ value is lower than would typically be the case for such a source. On the other hand, the usual candidates for drivers of field line resonance Kelvin-Helmholtz instability, cavity/waveguide excitation at the magnetopause, direct solar wind excitation - all provide tailward propagation. Sunward propagation (westward on the afternoon side) has been previously observed (Mathews et al., 2004; Eriksson et al., 2008) and was attributed to oscillations generated by earthward flows in the magnetotail. Unfortunately, no suitable data sets have been found for these events from instruments mapping to the magnetotail. The quiet conditions allow phenomena such as the socalled TRINNI events (e.g. Grocott et al., 2005). We propose that a viable mechanism is the generation of a fast wave by the velocity disturbance associated with such an event. The identification of the sources of various kinds of pulsation is a problem that still requires extensive study.

\section{Data availability}

The SuperDARN data (Virginia Tech, 2016) are available from the SuperDARN network (http: //vt.superdarn.org/). The Greenland magnetometer data (DTU Space, 2015) are free and available on request (http://www.space.dtu.dk/English/Research/Scientific data_and_models/Magnetic_Ground_Stations). The CARISMA, IMAGE and DST data are available at www.carisma.ca (University of Alberta, 2016), http: //space.fmi.fi/image/reqform/dataform.html (FMI, 2016) and http://wdc.kugi.kyoto-u.ac.jp/dst_final/index.html (World Data Center for Geomagnetism, 2016), respectively.

Acknowledgements. The authors acknowledge the use of SuperDARN data. SuperDARN is a collection of radars funded by the national scientific funding agencies of Australia, Canada, China, France, Japan, South Africa, the United Kingdom and the United States of America. The Sanae radar is operated by the South African National Space Agency (SANSA), with data management by the University of KwaZulu-Natal supported by NRF grant SNA14071877221. We wish to thank the National Space Institute at the Technical University of Denmark (DTU Space) for providing Greenland magnetometer data. We thank I. R. Mann, D. K. Milling and the rest of the CARISMA team for data. CARISMA is operated by the University of Alberta, funded by the Canadian Space Agency. We thank the IMAGE magnetometer array teams for making data available. We acknowledge the WDC for Geomagnetism, Kyoto, and participating observatories for the supply of DST data.

The topical editor, G. Balasis, thanks K.-H. Glassmeier, B. Heilig, and one anonymous referee for help in evaluating this paper.

\section{References}

Agapitov, O., Glassmeier, K.-H., Plaschke, F., Auster, H.-U., Constantinescu, D., Angelopoulos, V., Magnes, W., Nakamura, R., Carlson, C. W., Frey, S., and McFadden J. P.: Surface waves and field line resonances: A THEMIS case study, J. Geophys. Res., 114, A00C27, doi:10.1029/2008JA013553, 2009

Baker, K. B. and Wing, S.: A new magnetic coordinate system for conjugate studies at high latitudes, J. Geophys. Res., 94, 91399144, doi:10.1029/JA094iA07p09139, 1989.

Balasis, G., Daglis, I. A., Zesta, E., Papadimitriou, C., Georgiou, M., Haagmans, R., and Tsinganos, K.: ULF wave activity during the 2003 Halloween superstorm: multipoint observations from CHAMP, Cluster and Geotail missions, Ann. Geophys., 30, 1751-1768, doi:10.5194/angeo-30-1751-2012, 2012.

Balasis, G., Daglis, I. A., Mann, I. R., Papadimitriou, C., Zesta, E., Georgiou, M., Haagmans, R., and Tsinganos, K.: Multi-satellite study of the excitation of Pc3 and Pc4-5 ULF waves and their penetration across the plasmapause during the 2003 Halloween superstorm, Ann. Geophys., 33, 1237-1252, doi:10.5194/angeo33-1237-2015, 2015.

Bland, E. C., McDonald, A. J., Menk, F. W., and Devlin, J. C.: Multipoint visualization of ULF oscillations using the Super Dual Auroral Radar Network, Geophys. Res. Lett., 41, 6314-6320, doi:10.1002/2014GL061371, 2014.

Chen, L. and Hasegawa, A.: A theory of long-period magnetic pulsations, 1, Steady state excitation of field line resonance, J. Geophys. Res., 79, 1024-1032, doi:10.1029/JA079i007p01024, 1974.

Chisham, G., Lester, M., Milan, S. E., Freeman, M. P., Bristow, W. A., Grocott, A., McWilliams, K. A., Rouhoniemi, J. M., Yeoman, T. K., Dyson, P. L., Greenwald, R. A., Kikuchi, T., Pinnock, M., Rash, J. P. S., Sato, N., Sofko, G. J., Villain, J.P., and Walker, A. D. M.: A decade of the Super Dual Auroral Radar Network (SuperDARN): Scientific achievements, New technique and future directions, Surv. Geophys., 28, 33-109, doi:10.1007/s10712-007-9017-8, 2007.

DTU Space (Technical University of Denmark, National Space Institute): Magnetic Ground Stations, available at: http://www.space.dtu.dk/English/Research/Scientific_data_and_ models/Magnetic_Ground_Stations, last access: 19 October 2015.

Dungey, J. M.: Electrodynamics of the outer atmosphere, Penn State Ionosph. Res. Lab. Report 69, 1954.

Dungey, J. M.: Effects of electromagnetic perturbations on particles trapped in the radiation belts, Space Sci. Rev., 4, 199-222, doi:10.1007/BF00173882, 1965.

Eriksson, P. T. I., Blomberg, L. G., Schaefer, S., and Glassmeier, K.-H.: Sunward propagating Pc5 waves observed on the postmidnight magnetospheric flank, Ann. Geophys., 26, 1567-1579, doi:10.5194/angeo-26-1567-2008, 2008.

Fenrich, F. R., Samson, J. C., Sofko, G., and Greenwald, R. A.: ULF high- and low-m field line resonances observed with the Super Dual Auroral Radar Network, J. Geophys. Res., 100, 2153521547, doi:10.1029/95JA02024, 1995.

FMI (Finnish Meteorological Institute): IMAGE data, available at: http://space.fmi.fi/image/reqform/dataform.html, last access: 27 September 2016.

Glassmeier, K.-H.: Magnetometer array observations of a giant pulsation event, J. Geophys.-Z. Geophys., 48, 127-138, 1980. 
Greenwald, R. A., Baker, K. B., Dudeney, J. R., Pinnock, M., Jones, T. B., Thomas, E. C., Villain, J.-P., Cerisier, J.-C., Senior, C., Hanuise, C., Hunsucker, R. D., Sofko, G., Koehler, J., Nielsen, E., Pellinen, R., Walker, A. D. M., Sato, N., and Yamagishi, H.: DARN/SuperDARN: A global view of high latitude convection, Space Sci. Rev., 71, 761-796, doi:10.1007/BF00751350, 1995.

Grocott, A., Badman, S. V., Cowley, S. W. H., Yeoman, T. K., and Cripps, P. J.: The influence of IMF By on the nature of the nightside high-latitude ionospheric flow during intervals of positive IMF Bz, Ann. Geophys., 22, 1755-1764, doi:10.5194/angeo-221755-2004, 2004.

Grocott, A., Yeoman, T. K., Milan, S. E., and Cowley, S. W. $\mathrm{H}$.: Interhemispheric observations of the ionospheric signature of tail reconnection during IMF-northward non-substorm intervals, Ann. Geophys., 23, 1763-1770, doi:10.5194/angeo-231763-2005, 2005.

James, M. K., Yeoman, T. K., Mager, P. N., and Klimushkin, D. Y.: The spatio-temporal characteristics of ulf waves driven by substorm injected particles, J. Geophys. Res., 118, 1-13, doi:10.1002/jgra.50131, 2013.

Kepko, L., Spence, H. E., and Singer, H. J.: ULF waves in the solar wind as direct drivers of magnetospheric pulsations, Geophys. Res. Lett., 29, 1197, doi:10.1029/2001GL014405, 2002.

Kivelson, M. G. and Southwood, D. J.: Resonant ULF waves: A new interpretation, Geophys. Res. Lett., 12, 49-52, doi:10.1029/GL012i001p00049, 1985.

Mann, I. R., Wright, A. N., Mills, K. J., and Nakariakov, V. M.: Excitation of magnetospheric waveguide modes by magnetosheath flows, J. Geophys. Res., 104, 333-353, doi:10.1029/1998JA900026, 1999.

Mann, I. R., Milling, D. K., Rae, I. J., Ozeke, L. G., Kale, A., Kale, Z. C., Murphy, K. R., Parent, A., Usanova, M., Pahud, D. M., Lee, E.-A., Amalraj, V., Wallis, D. D., Angelopoulos, V., Glassmeier, K.-H., Russell, C. T., Auster, H.-U., and Singer, H. J.: The upgraded CARISMA magnetometer array in the THEMIS era, Space Sci. Rev., 141, 413-451, doi:10.1007/s11214-008-9457-6, 2008.

Magnus, L.: An analysis of Pc5 pulsations observed in the SuperDARN radar data, PhD thesis, University of KwaZulu-Natal, Durban, South Africa, 2010.

Mathews, J. T., Mann, I. R., Rae, I. J., and Moen, J.: Multiinstrument observations of ULF wave-driven discrete auroral arcs propagating sunward and equatorward from the poleward boundary of the duskside auroral oval, Phys. Plasmas, 11, 1250, doi:10.1063/1.1647137, 2004.

Mtumela, Z., Stephenson, J. A. E. and Walker, A. D. M.: An investigation of the nature of a Pc5 pulsation event using SuperDARN and magnetometer data, S. Afr. J. Sci., 111, 2013-0391, doi:10.17159/sajs.2015/20130391, 2015.

Nielsen, E.: Observations of Sunward Propagating Waves on the Magnetopause, J. Geophys. Res., 89, 9095-9099, doi:10.1029/JA089iA10p09095, 1984.

Pilipenko, V. A., Klimushkin, D. Yu., Mager, P. N., Engebretson, M. J., and Kozyreva, O. V.: Generation of resonant Alfvén waves in the auroral oval, Ann. Geophys., 34, 241-248, doi:10.5194/angeo-34-241-2016, 2016.

Ponomarenko, P. V., Menk, F. W., and Waters, C. L.: Visualization of ULF waves in SuperDARN data, Geophys. Res. Lett., 30, 1926, doi:10.1029/2003GL017757, 2003.
Poole, A. W. V., Sutcliffe, P. R. and Walker, A. D. M.: The relationship between ULF geomagnetic pulsations and ionospheric Doppler oscillations: Derivation of a model, J. Geophys. Res., 93, 14656-14664, doi:10.1029/JA093iA12p14656, 1988.

Samson, J. C., Greenwald, R. A., Ruohoniemi, J. M., Hughes, T. J., and Wallis, D. D.: Magnetometer and radar observations of magnetohydrodynamic cavity modes in the Earth's magnetosphere, Can. J. Phys., 69, 929-937, doi:10.1139/p91-147, 1991.

Samson, J. C., Harrold, B. G., Ruohoniemi, J. M., Greenwald, R. A., and Walker A. D. M.: Field line resonances associated with MHD waveguides in the Earth's magnetosphere, Geophys. Res. Lett., 19, 441-444, doi:10.1029/92GL00116, 1992.

Shepherd, S. G.: Altitude-adjusted corrected geomagnetic coordinates: Definition and functional approximations, J. Geophys. Res.-Space, 119, 7501-7521, doi:10.1002/2014JA020264, 2014

Southwood, D. J.: The hydromagnetic instability of the magnetospheric boundary, Planet. Space Sci., 16, 587,-605, doi:10.1016/0032-0633(68)90100-1, 1968.

Southwood, D. J.: Some features of field line resonances in the magnetosphere, Planet. Space Sci., 22, 483-491, doi:10.1016/00320633(74)90078-6, 1974.

Stephenson, J. A. E. and Walker, A. D. M.: HF observations of Pc5 pulsations driven by the solar wind, Geophys. Res. Lett., 29, 81-8-4, doi:10.1029/2001GL014291, 2002.

Stephenson, J. A. E. and Walker, A. D. M.: Coherence between radar observations of magnetospheric field line resonances and discrete oscillations in the solar wind, Ann. Geophys., 28, 4759, doi:10.5194/angeo-28-47-2010, 2010.

Sutcliffe, P. R. and Poole, A. W. V.: Ionospheric Doppler and electron velocities in the presence of ULF waves, J. Geophys. Res., 94, 13505-13514, doi:10.1029/JA094iA10p13505, 1989.

Sutcliffe, P. R. and Poole, A. W. V.: The relationship between ULF geomagnetic pulsations and ionospheric Doppler oscillations: Model predictions, Planet. Space Sci., 38, 1581-1589, doi:10.1016/0032-0633(90)90165-M, 1990.

Tamao, T.: Transmission and coupling resonance of hydromagnetic disturbances in the nonuniform Earths magnetosphere, Sci. Rep. Tohoku Univ. Geophys., 17, 43-72, 1965.

Tanskanen, E. I.: A comprehensive high-throughput analysis of substorms observed by IMAGE magnetometer network: Years 1993-2003 examined, J. Geophys. Res., 114, A05204, doi:10.1029/2008JA013682, 2009.

University of Alberta: CARISMA data, available at: www.carisma. ca, last access: 27 September 2016.

Virginia Tech: SuperDARN data, available at: http://vt.superdarn. org/, last access: 27 September 2016.

Walker, A. D. M.: Modelling of Pc5 pulsation structure in the magnetosphere, Planet. Space Sci., 28, 213-223, doi:10.1016/00320633(80)90014-8, 1979.

Walker, A. D. M.: The Kelvin-Helmholtz instability in the lowlatitude boundary layer, Planet. Space Sci. 29, 1119-1133, doi:10.1016/0032-0633(81)90011-8, 1981.

Walker, A. D. M.: Excitation of field line resonances by MHD waves originating in the solar wind, J. Geophys. Res., 107, 1481, doi:10.1029/2001JA009188, 2002.

Walker, A. D. M., Rouhoniemi, J. M., Baker, K. B., Greenwald, R. A., and Samson, J. C.: Spatial and temporal behavior of ULF pulsations observed by the Goose Bay HF radar, J. Geophys. Res., 97, 12187-12202, doi:10.1029/92JA00329, 1992. 
Walker, A. D. M., Pinnock, M., Baker, K. B., Dudeney, J. R., and Rash, J. P. S.: Strong flow bursts in the nightside ionosphere during extremely quiet solar wind conditions, Geophys. Res. Lett., 25, 881-884, doi:10.1029/98GL00408, 1998.

Walker, A. D. M., Baker, K. B., Pinnock, M., Dudeney, J. R., and Rash, J. P. S.: Radar observations of magnetospheric activity during extremely quiet solar wind conditions, J. Geophys. Res., 107, 1038, doi:10.1029/2001JA000063, 2002.

Waters, C. L., Yeoman, T. K., Sciffer, M. D., Ponomarenko, P., and Wright, D. M.: Modulation of radio frequency signals by ULF waves, Ann. Geophys., 25, 1113-1124, doi:10.5194/angeo-251113-2007, 2007.
World Data Center for Geomagnetism: Final Dst index, available at: http://wdc.kugi.kyoto-u.ac.jp/dst_final/index.html, last access: 27 September 2016.

Ziesolleck, C. W. S., Fenrich, F. R., Samson, J. C., and McDiarmid, D. R.: Pc5 field line resonance frequencies and structure observed by SuperDARN and CANOPUS, J. Geophys. Res., 103, 11771-11785, doi:10.1029/JA094iA02p01479, 1998. 